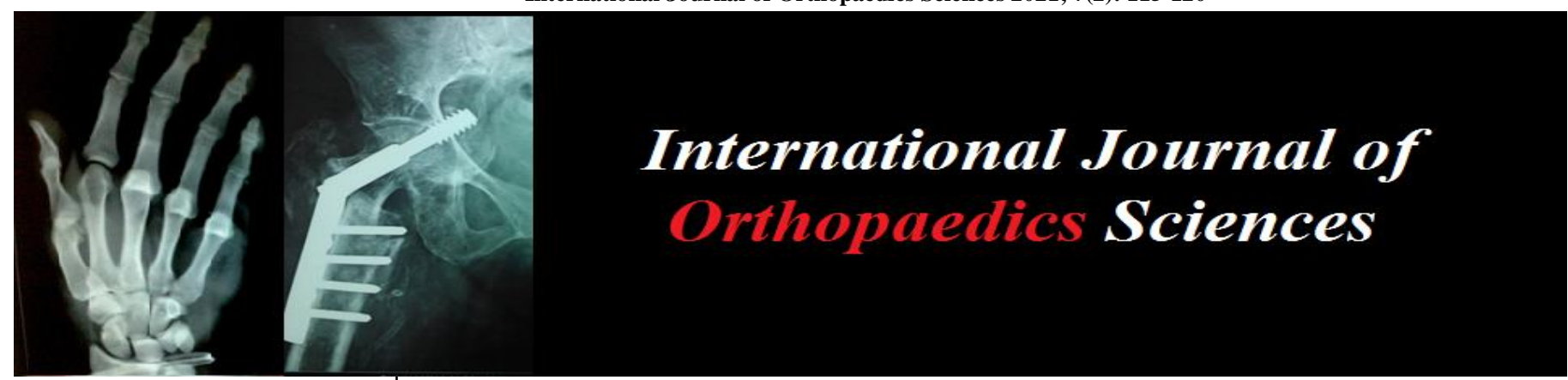

E-ISSN: 2395-1958

P-ISSN: 2706-6630

IJOS 2021; 7(2): 115-120

(C) 2021 IJOS

www.orthopaper.com

Received: 21-02-2021

Accepted: 23-03-2021

\section{Jagdeep Singh}

Associate Professor, Department

of Orthopaedics, Guru Gobind

Singh Medical College and

Hospital, Faridkot, Punjab, India

\section{Sorabh Garg}

Senior Resident, Department of

Orthopaedics, Guru Gobind

Singh Medical College and

Hospital, Faridkot, Punjab,

India

\section{Anoop Kalia}

Clinical fellow in Arthroplasty, Department of Orthopaedics,

Max Super Speciality Hospital,

Mohali, Punjab, India

Karan Rajpal

Senior Resident,

Department of Orthopaedics,

NDMC, Medical College and

Hindu Rao Hospital, New Delhi, India

Swarnesh Baskaran

Senior Resident, Department of

Orthopaedics, Guru Gobind

Singh Medical College and

Hospital, Faridkot, Punjab,

India

Amit Sharma

Senior Resident,

Department of Orthopaedics.

Amandeep Hospital, Pathankot,

Punjab, India
Corresponding Author: Sorabh Garg

Senior Resident, Department of Orthopaedics, Guru Gobind

Singh Medical College and

Hospital, Faridkot, Punjab,

India

\section{Minimally invasive plate osteosynthesis for humerus diaphyseal fractures: A retrospective study}

\author{
Jagdeep Singh, Sorabh Garg, Anoop Kalia, Karan Rajpal, Swarnesh \\ Baskaran and Amit Sharma
}

DOI: https://doi.org/10.22271/ortho.2021.v7.i2b.2621

\section{Abstract}

Introduction: Several authors have reported anterior bridge plating of humerus as an acceptable and satisfactory procedure for treatment for humerus shaft fractures.

We evaluated the clinical, radiological and functional outcome of such fractures over a period of follow up of 12 months treated by MIPO technique.

Materials and Methods: Twenty patients presenting to author institute on follow up with humerus shaft fractures treated with anterior bridge plating using MIPO technique between January 2015 - December 2018. In all cases $4.5 \mathrm{~mm}$ dynamic compression plate (DCP) was used. The surgery time, radiation exposure and time for union was noted using hospital records. The shoulder and elbow function was assessed using UCLA (The University Of California At Los Angeles)shoulder and Mayo elbow performance score respectively.

Results: Out of the 20 patients, 14 were male and 6 females. The mean age was 38.2 years (range 20 to $68) .14$ out of 20 patients (70\%) had dominant side fractured.

Mean surgical time was 82.7 minutes (range 60-120 minutes). Mean radiation exposure counted as one second for C- arm exposure was 112 seconds (80-170). The mean time for union was 13.4 weeks (range10 -20 weeks). Shoulder function was excellent in 17 patients $(85 \%)$ and good in remaining 3 patients $(15 \%)$ according to the UCLA score.elbow function was excellent in 15 cases $(75 \%)$ and good in 5 cases $(25 \%)$.

Conclusion: Anterior bridge plating ofhumerusis an effective treatment for humerus shaft fractures and as the surgeon keep on gaining experience in this technique, it becomes less time consuming.

Keywords: Diaphyseal, bridge plating, union

\section{Introduction}

One to two percent of the fractures of the human body comprise of shaft humerus fractures. However fracture of humerus shaft constitutes $14 \%$ of entire humerus fractures ${ }^{[1]}$. These fractures have numerous modes of injury with osteoporosis being responsible for severity of injury ${ }^{[2]}$.

The target of treatment therapy is the reduction of fracture, thereby maintaining the reduction in proper alignment, length and rotation and facilitating early movement to avoid stiffness. Perfect anatomic reduction and absolute stable fixation has its own consequenses ${ }^{[3]}$.

Humerus shaft fracture treatments has evolved from conservative cast and braces ${ }^{[4,5]}$ to internal fixation with plates and nails ${ }^{[6]}$.

No technique has been shown to superior over another. MIPO for humerus shaft fractures has recently shown some promising results ${ }^{[7-10]}$.

We evaluated the clinical, radiological and functional outcome of such fractures over a period of follow up of 12 months treated by MIPO technique.

\section{Materials and Methods}

A Retrospective study was conducted in a Author institute where Twenty humerus shaft fractures patients presenting to opd, treated with anterior bridge plating using MIPO technique between January 2015 - January 2018 were taken. These patients were followed up for a minimum period of 12 months. In all cases $4.5 \mathrm{~mm}$ dynamic compression plate (DCP) was used. 
Patients included in the study were the ones with closed diaphysealhumerus fractures, fracture to operate duration less than 7 days, skeletally mature patient and the patients Excluded from the study were patients with fractures on both limbs at the time of presentation, fracture duration more than 7 days old, skeletally immature patients, pathological fractures, patients treated along with other comorbidities like vascular insufficiency of upper limb.

\section{Surgical Technique Used}

The patients were positioned supine. Out of the 20 patients, 14 were given general anesthesia and 6 patients were given brachial block. The image intensifier was positioned on same side of operating table as the side to be operated.

The surgical technique which was used was similar to the one described by levani and belangero ${ }^{[11]}$.

Proximally, a $3 \mathrm{~cm}$ incision was made between biceps and medial border of deltoid, $5 \mathrm{~cm}$ distal to acromion process. Distally a $3 \mathrm{~cm}$ incision was made along lateral border of biceps about $5 \mathrm{~cm}$ proximal to flexion crease as shown in FIG 1. The musculocutaneous nerve overlies brachialis muscle and it was exposed by retracting biceps medially. Brachialis muscle was split, musculocutaneous nerve retracted medially. The radial nerve was protected by lateral half of brachialis muscle. A sub-brachialis extraperiosteal tunnel was made using a dilation instrument from distal to proximal as shown in FIG 2,3. The plate of appropriate length was then slide from distal to proximal.

Varus/valgus angulation, length and rotation were controlled by manual traction and confirming the reduction, the plate was temporarily fixed with two $\mathrm{k}$ wires.

Two or three screws were used proximally and distally leaving the maximum possible empty holes between the screws as shown in FIG 4.

The rotational malaginment was checked using "cortical step" sign described by Krettek et al. ${ }^{[12]}$

None of the patients required bone grafting, however bone marrow infiltration was done in one patient.

\section{Follow UP}

Post operatively an anteroposterior and lateral radiograph was obtained as shown in FIG 5. Arm sling pouch was given to the patient for 3 weeks. However they were instructed to perform the range of motion exercises for 5 minutes after every 2 hours. Stiches were removed after 2 weeks. after 3 weeks, arm sling was discontinued and patients were trained by a dedicated physiotherapist to perform desired ROM (Range Of Motion) exercises. The final aim of the whole rehabilitation program as to achieve full and painless range of motion. The union time was noted. The patients were followed up by an independent surgeon every month for the first 6 months and then once in every 3 months till one year. The minimum follow up for every patient was aleast one year. At the end of one year the shoulder and elbow function was assessed using UCL Ashoulder [13] and Mayo elbow performance score ${ }^{[14]}$ respectively. UCLA shoulder score was graded into:

Excellent (34-35 points), good (29-33points), fair (2128points), poor (0-20 points)

Mayo elbow performance score was graded into excellent (>90points), good (75-89points), fair (60-74points) and poor (<60points)

Union was defined as absence of pain and presence of bridging callus in 3 out of 4 cortices on the anteroposterior and lateral radiographs as shown in FIG 6.

\section{Results}

Out of the 20 patients, 14 were male and 6 females. The mean age was 38.2 years (range 20 to 68 ). 14 out of 20 patients $(70 \%)$ had dominant side fractured.

The mode of injury was road traffic accident(RTA) in 16 cases (80\%), 3 patients had direct blow in the form of assault and one patient sustained fall on the outstretched hand as mode of injury.

The mean surgical time was 82.7 minutes (range 60-120 minutes)

The mean radiation exposure was 112 seconds (80-170). The mean time for union was 13.4 weeks (range10 -20 weeks) Shoulder function was excellent in 17 patients $(85 \%)$ and good in remaining 3 patients (15\%) according to the UCLA score as shown in FIG 7. elbow function was excellent in 15 cases $(75 \%)$ and good in 5 cases $(25 \%)$ as shown in FIG 8, 9. Observations were as depicted in the Table no.1.

In one case satisfactory callus was not seen at 13 weeks, so was infiltrated with bone marrow from iliac crest and the fracture united at 20 weeks.

In 3 cases post-operative sensory deficit over lateral half of forearm due to injury to musculocutaneous nerve was noted which recovered completely within 7 months. In one case there was radial nerve palsy post operatively because the patient was morbidly obese and we inadvertently went more lateral than usual but it recovered completed within 9 months. We accepted upto 5 degrees of varus/valgus angulation out of the 20 cases at final follow up, angulation had remodeled itself in 14 cases at final follow up. Amongst the remaining 6 cases, 3 had 3 degrees of varus angulation, 2 cases had 3 degree of valgus angulation and one patient had 5 degree of varus angulation but this did not accept their functional outcome.

\section{Discussion}

MIPO was first used by Krettek and Tscherene in supracondylar femur fractures in $1996{ }^{[15]}$. Numerous advantages are associated with this technique. It provides advantage of achieving consolidation with greater speed without interrupting the fracture hematoma and also without destructively shedding the soft tissue envelope [11]. By employing long plates, there is significant reduction in the stress per unit area which further decreases the risk of plate failure. The entire construct becomes elastic ${ }^{[16,17]}$.

Literature quotes fair results associated with MIPO for shaft humerus fractures. MIPO reduces the surgical damage to soft tissue and sustains the periosteal circulation. By application of plate on bone by open technique destroys the perisosteal blood supply resulting in osteonecrosis beneath the plate thus risking for non- union or delayed union.

In open technique, the associated primary bone healing is weak in nature and cases with re-fracture following implant removal have been reported $[18,19]$. Significant entry point problems like rotator cuff impingement ${ }^{[20]}$ are found to be associated with Interlocking nailing in humerus fractures. However; minimal evidence has been reported in relation to such instances in MIPO technique. In the original technique described by Livani and Belangero ${ }^{[11]}$, radioscopy was not used as an aid in reducing the fracture. It was reduced using the parameter of the intercondylar axis of the humerus, positioned perpendicularly to the axis of the biceps tendon, in order to correct any rotational displacement.

The fixation was performed at $60^{\circ}$ of abduction so that varus would be avoided. During follow up of the patients, the bone callus was observed and it was found that in these fractures 
with a simple line, consolidation also occurred with formation of a bone callus, even though not as abundant as seen in longbone fractures in the lower limbs. This perhaps occurs because of correlation with Wolf's law, which governs the use of forces and loads on the limb to stimulate the formation of bone callus, which does not occur profusely in the upper limbs.

By using long plates, stable synthesis is produced. The layout, number and location of the screws give rise to a wide working area, thus promoting relative stability.

The duration of radiation exposure in our series was 112 seconds (range: 80-170 seconds), our initial cases taking a longer duration due to our learning curve. Similar decreasing trend of radiation exposure was obtained by Shetty et al. in his study [21]

Since this is a technique for relative stability, in which movement at the focus is necessary in order to stimulate bone callus formation, it could be seen that using two distal screws was sufficient for fixation, without the need for a third screw. Livani and Belangero ${ }^{11}$ initially used three proximal and three distal screws in their work. In following up these patients, they noted that this method did not produce any profusion of callus, and they started to use two proximal and two distal screws.

Neuropraxia of the radial nerve is one of the most common complications of diaphyseal fractures of the humerus. In a study presented by some authors ${ }^{[19]}$. Since injury of the radial nerve is a disastrous intraoperative complication in humeral shaft fractures, iatrogenic radial nerve palsy was evaluated separately in our meta-analysis. MIPO, as previously noted, has the advantage of no need for radial nerve exposure. The total rate of iatrogenic radial nerve palsy in MIPO was $2.20 \%$ $(3 / 136)$ in five studies, which was significantly lower than that in ORPO $(10.45 \%, 14 / 134, p=0.01)$. However, rich anatomical knowledge and long learning curve is required for MIPO. Otherwise, MIPO may lead to a high rate of radial nerve palsy or nonunion ${ }^{[22]}$.

Neuropraxia occurred frequently when the method of open reduction and internal fixation was used, and it was also caused by the fracture itself improper and imprecise use of spacers may lead to injury of the radial nerve. This complication may beavoided by having a well trained having thorough knowledge of anatomy. According to the technique of Livani and Belangero ${ }^{[1]}$, division of thebrachial muscle is important in order to protect the radial nerve, thereby making the surgical technique possible without viewing and dissecting this nerve. It should also be emphasized that this muscle has double innervation, such that the medial belly is innervated by the musculocutaneous nerve and the lateral belly by the radial nerve. Thus, the brachial muscle can be divided in the middle, along its entire length, without the posterior portion losing its function.

Apivatthakakul T et al. ${ }^{[7]}$ reported that when a plate is placed on the anterior side of the humeral shaft, the mean distance from the closest part of the plate to the radial nerve is $3.2 \mathrm{~mm}$. They also pointed out that when the forearm was pronated, the radial nerve was noted to move medially closer to the distal end of the plate and was at risk of iatrogenic injury. For this reason, the supination position of the forearm should be maintained during the operation.

We observed in our study the MIPO albeit a newer technique in the armamentarium of the surgeon produces good results in a short of time with quicker union time and better cosmesis and less scars and as the surgeon grows in experience his surgical time reduces and this technique becomes more surgeon friendly.

However, the limitation of our study is that there was no control group for comparison or a group which was treated by some other method of fixation of humerus diaphyseal fracture, Less number of patients were taken into consideration, did not compare results of open Vs MIPO but still there are studies which show MIPO is effective and gives better results ${ }^{[22,24]}$.

\section{Conclusion}

We firmly believe that managing diaphyseal fractures of the humerus using the principles of biological fixation by means of a bridge plate constitutes a useful tool in orthopaedic surgeon's armamentarium. This technique presents low rates of complications and morbidity, good initial results, full rehabilitation and good patient satisfaction.

\section{List of Abbreviations}

1. MIPO: Minimally Invasive Plate Osteosynthesis

2. Dcp: Dynamic Compression Plate

3. Ucla: The University Of California At Los Angeles

4. Rom: Range Of Motion

5. Rta: Road Traffic Accident

\section{Acknowledgement: Not Applicable}

Authors Contribution: "AK, JS and SB developed the original idea. AK, JS, KR, AS abstracted the data. SG wrote the manuscript and is the guarantor. SG, KJ AND JS contributed to the development of protocol and edited the manuscript"

Data and Availability: All data generated or analysed during this study are included in this published article. Data are not available to other researchers because they are from an institutional database of patients providing routinely collected data.

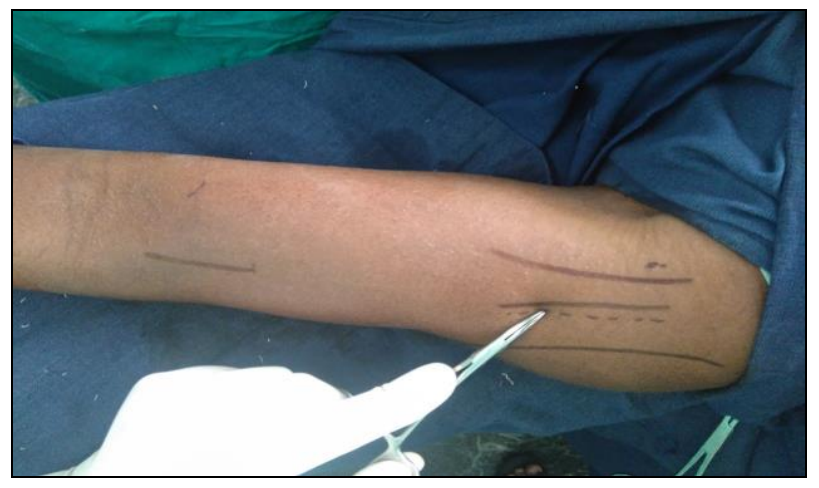

Fig 1: Showing the proximal and distal incision mark

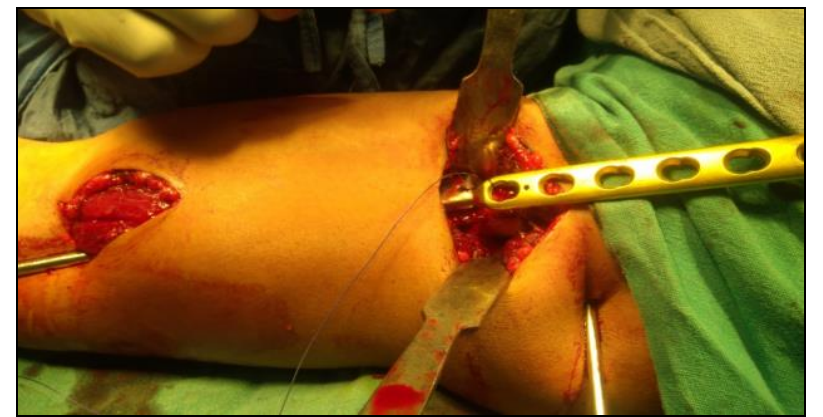

Fig 2: Showing intraoperative pic of dilator being passed from distal to proximal to create a tunnel for plate passage 


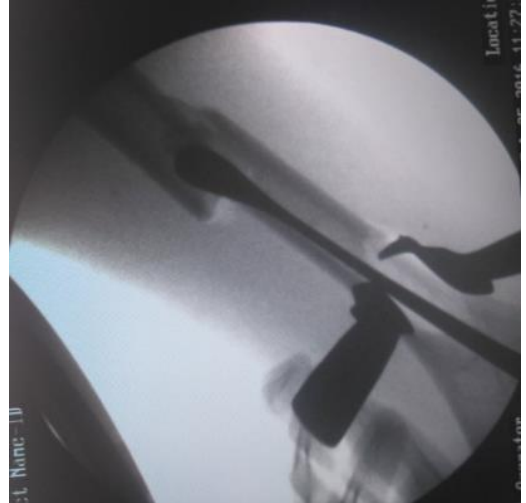

Fig 3: Showing IITV picture of dilator being passed

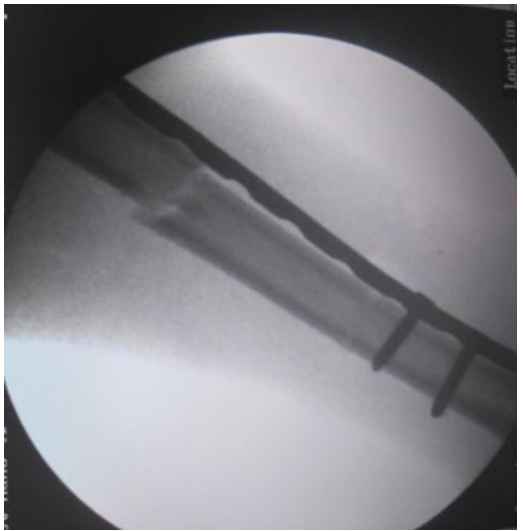

Fig 4: Showing C-ARM picture of distal most screws of plate being applied while leaving other holes empty

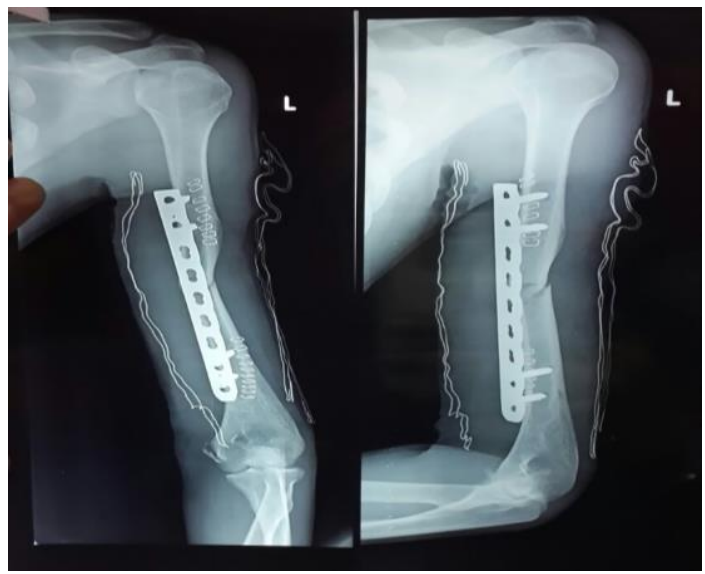

Fig 5: Showing immediate post-operative A.P and Lateral views

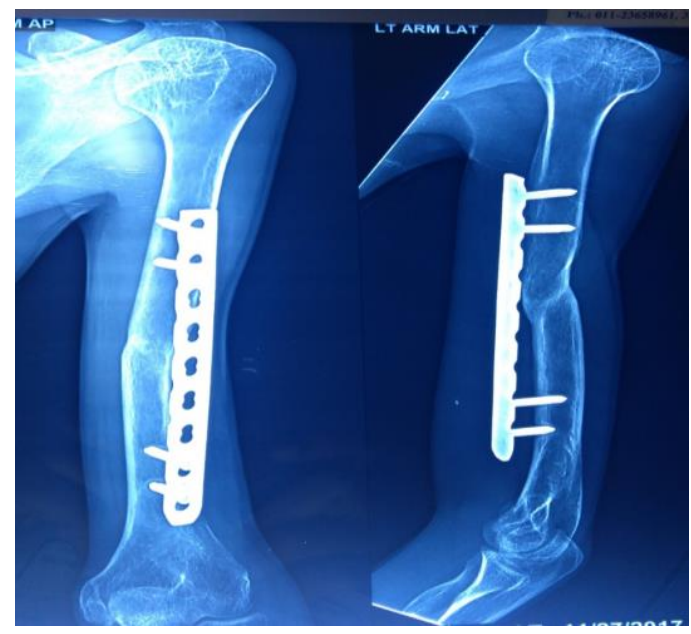

Fig 6: Showing solid union at the end of 12 months

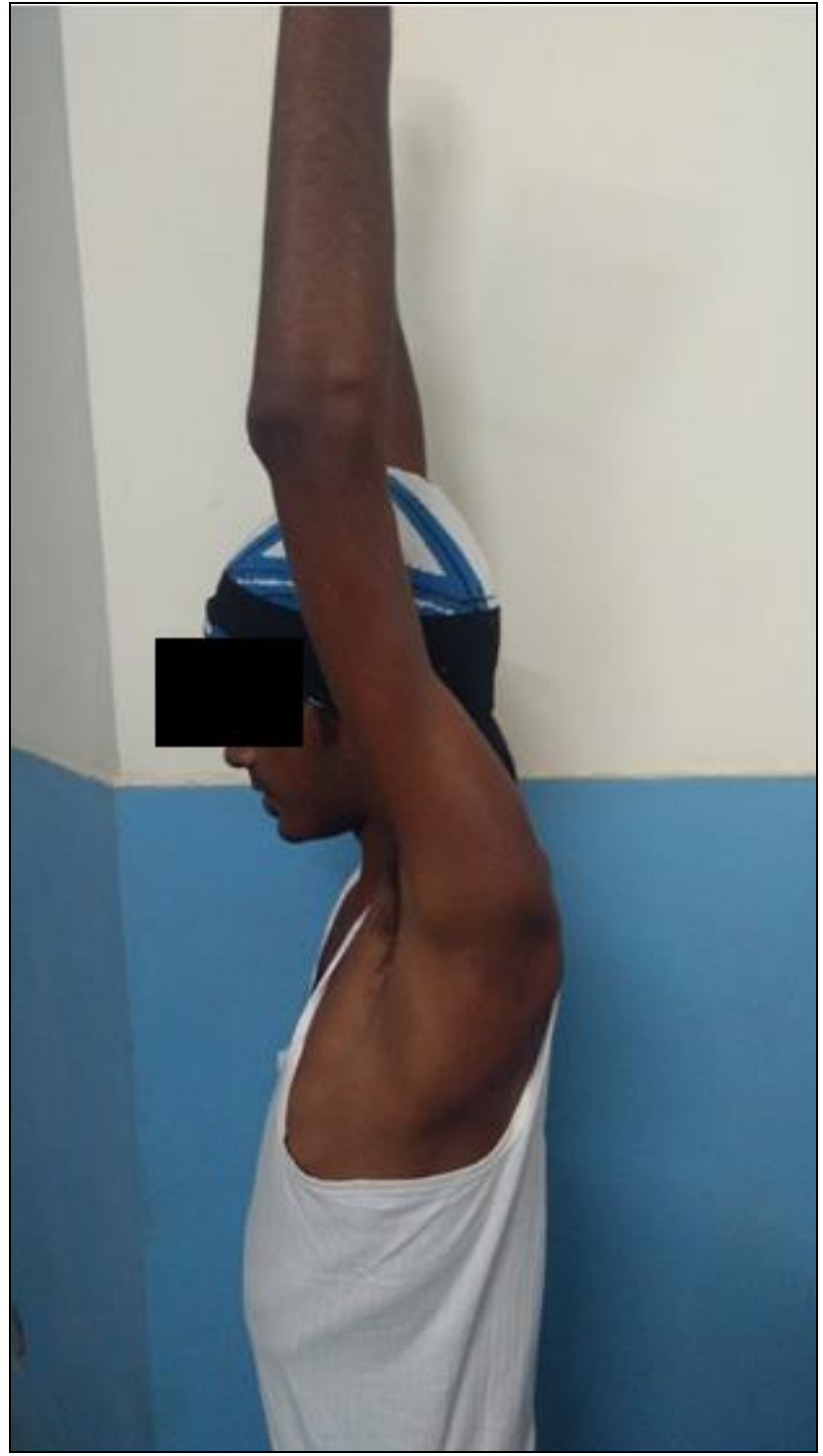

Fig 7: Showing shoulder range of motion

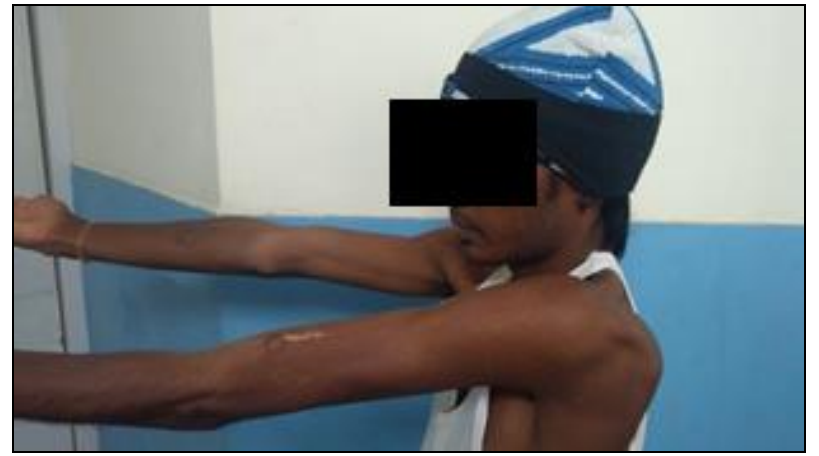

Fig 8: Showing elbow range of motion

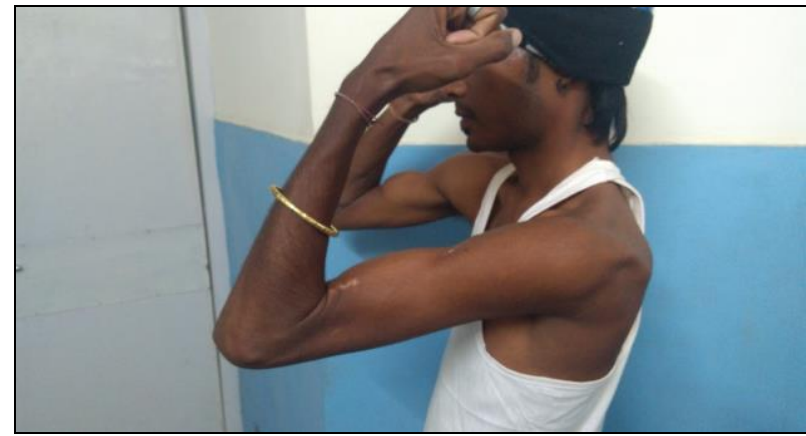

Fig 9: Showing elbow range of motion 
Table 1: Observations were as depicted

\begin{tabular}{|c|c|c|c|c|c|c|c|c|c|c|c|}
\hline \multirow{2}{*}{ S. } & \multirow{2}{*}{ Age } & \multirow{2}{*}{$\operatorname{sex}$} & \multirow{2}{*}{ Side } & \multirow{2}{*}{$\begin{array}{l}\text { Mech. of } \\
\text { injury }\end{array}$} & \multirow{2}{*}{\begin{tabular}{|c} 
Duration of \\
surgery \\
$(60-120$ \\
Min.)
\end{tabular}} & \multirow{2}{*}{$\begin{array}{c}\text { No. of c- } \\
\text { arm shots } \\
(80-170)\end{array}$} & \multirow{2}{*}{ Complications } & \multirow{2}{*}{$\begin{array}{l}\text { Time for union } \\
\text { (70-140 approx. } \\
\text { days) }\end{array}$} & \multicolumn{2}{|c|}{\begin{tabular}{|c|}
$\begin{array}{c}\text { Functional outcome (UCLA } \\
\text { Score) }\end{array}$ \\
\end{tabular}} & \multirow{2}{*}{$\begin{array}{c}\text { Angulation (5 } \\
\text { varus/ valgus } \\
\text { accepted) }\end{array}$} \\
\hline & & & & & & & & & Shoulder & Elbow & \\
\hline 1 & 35 & male & $\begin{array}{c}\text { Right } \\
\text { Dominant }\end{array}$ & rsa & 110 & 165 & no & 90 & Good & Excellent & Normal \\
\hline 2 & 45 & Female & $\begin{array}{c}\text { Right } \\
\text { Dominant }\end{array}$ & rsa & 105 & 158 & no & 105 & Excellent & Excellent & $3^{\circ}$ varus \\
\hline 3 & 50 & Male & $\begin{array}{c}\text { Non } \\
\text { Dominant }\end{array}$ & Rsa & 107 & 162 & No & 96 & Excellent & Excellent & Normal \\
\hline 4 & 65 & Male & $\begin{array}{c}\text { Right } \\
\text { Dominant }\end{array}$ & Rsa & 98 & 136 & No & 92 & Excellent & Excellent & Normal \\
\hline 5 & 58 & Male & $\begin{array}{c}\text { Left } \\
\text { Dominant }\end{array}$ & Rsa & 102 & 156 & No & 90 & Excellent & Excellent & $5^{\circ}$ varus \\
\hline 6 & 48 & Female & $\begin{array}{c}\text { Right } \\
\text { Dominant }\end{array}$ & Rsa & 92 & 145 & $\begin{array}{l}\text { Sensory Deficiet due to } \\
\text { musculocutaneous Nerve } \\
\text { Injury }\end{array}$ & 97 & Excellent & Excellent & Normal \\
\hline 7 & 56 & Male & $\begin{array}{c}\text { Right } \\
\text { Dominant }\end{array}$ & Rsa & 106 & 134 & No & 102 & Good & Excellent & Normal \\
\hline 8 & 34 & Male & $\begin{array}{c}\text { Non } \\
\text { Dominant }\end{array}$ & Rsa & 95 & 160 & No & 86 & Excellent & Excellent & $3^{\circ}$ varus \\
\hline 9 & 39 & Female & $\begin{array}{c}\text { Right } \\
\text { Dominant }\end{array}$ & Rsa & 88 & 124 & No & 88 & Excellent & Excellent & Normal \\
\hline 10 & 58 & Male & $\begin{array}{c}\text { Right } \\
\text { Dominant }\end{array}$ & Rsa & 105 & 117 & $\begin{array}{l}\text { Sensory Deficiet due to } \\
\text { musculocutaneous Nerve } \\
\text { Injury }\end{array}$ & 107 & Excellent & Good & Normal \\
\hline 11 & 45 & Male & $\begin{array}{c}\text { Non } \\
\text { Dominant }\end{array}$ & Assault & 84 & 133 & No & 103 & Excellent & Good & $3^{\circ}$ valgus \\
\hline 12 & 62 & Female & $\begin{array}{c}\text { Non } \\
\text { Dominant }\end{array}$ & Rsa & 111 & 144 & Radial Nerve Palsy & 108 & Excellent & Good & Normal \\
\hline 13 & 43 & Male & $\begin{array}{c}\text { Right } \\
\text { Dominant }\end{array}$ & Rsa & 98 & 114 & No & 95 & Excellent & Excellent & Normal \\
\hline 14 & 59 & Male & $\begin{array}{c}\text { Right } \\
\text { Dominant }\end{array}$ & Rsa & 76 & 99 & $\begin{array}{l}\text { Sensory Deficiet due to } \\
\text { musculocutaneous Nerve } \\
\text { Injury }\end{array}$ & 88 & Excellent & Excellent & Normal \\
\hline 15 & 24 & Male & $\begin{array}{c}\text { Right } \\
\text { Dominant }\end{array}$ & Rsa & 68 & 106 & No & 101 & Excellent & Excellent & $3^{\circ}$ varus \\
\hline 16 & 36 & Female & $\begin{array}{c}\text { Right } \\
\text { Dominant }\end{array}$ & Assault & 84 & 98 & No & 87 & Excellent & Excellent & Normal \\
\hline 17 & 53 & Male & $\begin{array}{c}\text { Non } \\
\text { Dominant }\end{array}$ & Rsa & 90 & 96 & No & 114 & Excellent & Excellent & Normal \\
\hline 18 & 64 & Female & $\begin{array}{c}\text { Right } \\
\text { Dominant }\end{array}$ & FOOSH & 64 & 104 & No & 112 & Good & Good & Normal \\
\hline 19 & 29 & male & $\begin{array}{c}\text { Non } \\
\text { Dominant }\end{array}$ & Assualt & 68 & 97 & No & 84 & Excellent & Good & $3^{\circ}$ valgus \\
\hline 20 & 33 & Male & $\begin{array}{c}\text { Right } \\
\text { Dominant }\end{array}$ & Rsa & 72 & 83 & No & 83 & Excellent & Excellent & Normal \\
\hline
\end{tabular}

Conflict of Interest: The authors declare that they have no conflict of interest.

Consent: The authors declare that they have taken proper consent from the patients for publication of data as well as photographs.

Funding: The authors declare that they did not receive any kind of funding from any source for conducting this study.

Ethical approval: This article does not contain any studies with human participants or animals performed by any of the authors.

\section{References}

1. Senko EI, Kudriavstev VP. (treatment of diaphyesal fractires of humerus and long bones). Khirugiia (Mosk) 1989;1:13-14.

2. Ekholm R, Adami J, Tidemark J, Hanson K, Törnkvist H, Ponser S. Fracturesof the shaft of the humerus: an epidemiological study of 401 fractures. J Bone Joint Surg Br 2006;88-B:1469-1473.

3. Frigg R, Wagner M. AO Manual of fracture management. Chapters 1.2: Concepts of fracture fixation 2006.
4. Camden P. Fracture bracing of the humerus. Injury 1992;23:245-8.

5. Hunter SG. The closed treatment of fractures of the humeral shaft. Clin Orthop Relat Res 1982;164:192-8.

6. Chao TC. Humeral shaft fractures treated by DCP, Ender and interlocking nails. Int Orthop 2005;29:88-91.

7. Apivatthakakul T, Arpornchayanon O, Bavornratanavech S. MIPO of the humeral shaft fracture: Is it possible? A cadaveric study and preliminary report. Injury 2005;36:530-8.

8. Zhiquan A. Minimally invasive plating osteosynthesis (MIPO) of middle and distal third humeral shaft fractures. J Orthop Trauma 2007;21:628-33.

9. Ziran BH. Percutaneous plating of the humerus with locked plating: Technique and case report. J Trauma In $\mathrm{j}$ Infect Crit Care 2007;63:205-10.

10. Livani B. Is MIPO in humeral shaft fractures really safe? Postoperative ultra sonographic evaluation. Int Orthop 2009;33:1719-23.

11. Livani B, Belangero WD. Bridging plate osteosynthesis of humeral shaft fractures. Injury, Int. J Care Injured. 2004;35:587-595.

12. Krettek C. Intra operative control of axes, rotation and length in femoral and tibial fractures- Technical note. 
Injury 1998;29(Suppl 3):C29-39.

13. Amstutz HC, Sew Hoy AL, Clarke IC. UCLA anatomic total shoulder arthroplasty. Clin Orthop Relat Res 1981;155:7-20.

14. Morrey BF, An KN, Chao EY. Functional evaluation of the elbow. In: Morrey BF, editor. The elbow and its disorders. 2nd ed. Philadelphia: W. B. Saunders 1993, 86-97.

15. Krettek C, Schandelmaier P, Tscherne H. Distal femoralfractures: Transarticular reconstruction, percutaneous plateosteosynthesis and retrograde nailing [in German]. Unfallchirug 1996;99:2-10.

16. Schmidtmann U, Knopp W, Wolff C, Stürmer KM. Results ofelastic plate osteosynthesis in polytraumatized patients: Analternative procedure. Unfallchirurg 1997;100:949-56.

17. Sturmer KM. Elastic plate osteosynthesis, biomechanics, indications and technique in comparison with rigidosteosynthesis. Unfallchirurg 1996;99:816-7.

18. Breederveld RS, Patka P, Van Mourik JC. Refractures of thefemoral shaft. Neth J Surg 1985;37:114.

19. Broos PL, Sermon A. From unstable internal fixation tobiological osteosynthesis a historical overview of operativefracture treatment. Acta Chir Belg. 2004;104:396-400.

20. Ajmal M, O’Sullivan M, McCabe J, Curtin W. Antegrade lockedintramedullary nailing in humeral shaft fractures. Injury 2001;32:692-4.

21. Shetty MS, Kumar AM, Sujay KT, Kini AR, Kanthi KG. Minimally invasive plate osteosynthesis for humerus diaphyseal fractures. Indian J Orthop 2011;45(6):520-26.

22. $\mathrm{Hu} \mathrm{X}, \mathrm{Xu} \mathrm{S}, \mathrm{Lu} \mathrm{H}$, Chen B, Zhou X, He X et al. Minimally invasive plate osteosynthesis vs conventional fixation techniques for surgically treated humeral shaft fractures: a meta-analysis. J Orthop Surg Res. 2016;11(1):59.

23. Oh CW, Byun YS, Oh JK, Kim JJ, Jeon IH, Lee JH, Park $\mathrm{KH}$. Plating of humeral shaft fractures: Comparison of standard conventional plating versus minimally invasive plating: Orthop Traumatol Surg Res 2012;98(1):54-60.

24. Hadhoud MM, Darwish AE, Mesriga MM. Minimally invasive plate osteosynthesis versus open reduction and plate fixation of humeral shaft fractures. Menoufia Med J 2015;28:154-61. 